\title{
JÚLIO RIBEIRO, AUTOR FUNDADOR?
}

\section{JÚLIO RIBEIRO, FOUNDING AUTHOR?}

\author{
José Edicarlos de Aquino \\ Universidade Federal do Tocantins, UFT, Porto Nacional, TO, Brasil
}

\begin{abstract}
Resumo: O presente trabalho procura compreender como se constrói a imagem de Júlio Ribeiro como um autor fundador na história dos estudos sobre a linguagem no Brasil, bem como autoprojeção de um lugar de destaque nos estudos gramaticais e linguísticos feita por ele próprio na sua obra. O objetivo é mostrar como se assenta, pela repetição de certos dizeres, a ideia de Júlio Ribeiro como uma figura desbravadora na gramatização brasileira do português no século XIX, discutindo os critérios que são empregados para colocá-lo na posiçấo de marco e ponto de origem na história das ideias linguísticas no Brasil.
\end{abstract}

Palavras-chave: Júlio Ribeiro; autor fundador; gramatização brasileira.

Abstract: The present work tries to understand how the image of Júlio Ribeiro is constructed as a founding author in the history of the studies on the language in Brazil, as well as selfprojection of a place of prominence in the grammar and linguistic studies made by Júlio Ribeiro in his own work. The objective is to show how the idea of Júlio Ribeiro as a pioneering figure in the Brazilian grammatization of Portuguese in the 19th century is constructed by repeating certain words, discussing the criteria that are used to place it in the position of landmark and point of origin in the history of linguistic ideas in Brazil.

Keywords: Julio Ribeiro; founding author; Brazilian grammatization.

\section{Apresentação}

Para o grande público, Júlio Ribeiro é o autor do romance $A$ Carne, um dos livros mais populares no Brasil desde a sua publicação em 1888. No mundo das letras, ele é também o autor da Grammatica Portugueza (1881). Nas pesquisas realizadas no eixo do projeto História das Ideias Linguísticas no Brasil, especificamente, é consenso tomá-lo como o discurso fundador da gramática no país, como a referência primeira na gramatização brasileira do português na segunda metade do século XIX.

O propósito deste estudo é justamente mostrar como se constrói, pela repetiçấo de certos dizeres, a ideia de Júlio Ribeiro como um autor fundador na história da gramatizaçáo brasileira. Dessa forma, analisando as pesquisas realizadas no eixo do projeto História das Ideias Linguísticas no Brasil e 
nas dissertaçóes e teses que nos últimos anos, a partir dessas pesquisas, têm tomado o autor como objeto de estudo, procuramos compreender o lugar de destaque atribuído a Júlio Ribeiro na história que se conta sobre as ideias linguísticas no Brasil. Olhando para a própria obra de Júlio Ribeiro, procuramos reconstituir também a maneira como ele se autorrepresenta como um autor fundador numa história brasileira de reflexão sobre a linguagem.

\section{Reconhecimento de Júlio Ribeiro como um autor fundador na grama- tizaçáo brasileira pelo programa da História das Ideias Linguísticas no Brasil}

A tomada de Júlio Ribeiro como o "primeiro gramático" do processo da gramatização brasileira se dá no reconhecimento de que existe um papel fundador na construçáo de um lugar brasileiro de dizer sobre a língua atribuído a ele por nomes decisivos na história da gramática do Brasil. Desse modo, Orlandi (2002, p. 131) defende que Júlio Ribeiro "se qualifica, na história da gramatização, como um lugar de referência absoluto, aquele que significa um discurso fundador da história da gramática brasileira”, acrescentando que "não é o uso de fato de sua gramática (na escola, por exemplo) que dá sua importância, mas o mecanismo de citaçáo que faz dele a referência primeira”. Essas afirmaçóes sintetizam um olhar sobre Júlio Ribeiro que se firma no programa da História das Ideias Linguísticas no Brasil, no qual então ele é significado, para aproveitar outra formulação de Orlandi (2002, p. 131-132), como "uma figura emblemática do processo de gramatização brasileira da língua nacional”, que "realiza de modo exemplar a relação Estado/Língua/Conhecimento Linguístico como autor nacional”, de forma que, com ele, "passamos a ter uma gramática brasileira para nossa língua".

Quando estabelece uma periodização para os estudos do português no Brasil, Guimarães (1994) situa Júlio Ribeiro, por via de sua gramática, no início do período correspondente à realização da gramatização do português no Brasil:

O primeiro período iria da "descoberta" em 1500 até a primeira metade do século XIX, momento em que se desenvolvem debates entre brasileiros e portugueses a propósito de construçóes consideradas inadequadas por escritores ou gramáticos portugueses. Deste momento é a célebre polêmica entre José de Alencar e Pinheiro Chagas; ou a polêmica entre Carlos de Laet e Camilo Castelo Branco. 
O segundo período iria da segunda metade do século XIX, iniciada pelos debates referidos no parágrafo anterior pela publicação de gramáticas como a de Júlio Ribeiro em 1881, pela fundaçâo da Academia Brasileira de Letras (em 1897), até fins dos anos 30, quando da fundação das Faculdades de Letras no Brasil. Tanto a Faculdade de Filosofia, Ciências e Letras da USP (em 1937) quanto a Faculdade Nacional de Letras da Universidade do Brasil (em 1939).

O terceiro período iria do final dos anos 30 até meados da década de 60, quando o Conselho Federal de Educação torna a Linguística disciplina obrigatória no Brasil, para os cursos de Letras.

O quarto período iria de meados dos anos 60 até hoje. Período em que a linguística se implantou em todos os cursos de graduaçấo em Letras e ao mesmo tempo foram implantados cursos de Pós-graduação em Linguística em alguns centros universitários brasileiros (GUIMARÃES, 1994).

É assim, dentro de uma reflexão sobre a história da gramatização brasileira, que Júlio Ribeiro entra no mapa dos estudos do projeto História das Ideias Linguísticas no Brasil. Orlandi e Guimarães (2001) ensinam que a gramatização brasileira é marcada pelo fato de a gramática no Brasil se distanciar da tradiçáo da gramática portuguesa, particularmente do modelo da gramática filosófica de Jerónimo Soares Barbosa. É nesse ponto que Júlio Ribeiro, posicionado como "um dos iniciadores da gramatização brasileira do português" (2001, p. 27), ganha toda sua importância. A partir das consideraçôes de Orlandi e Guimarães (2001), quanto à recusa de Júlio Ribeiro da tradição estabelecida por Barbosa, pela definição da gramática como exposição metódica dos fatos da linguagem, que Orlandi (2009, p. 54) vai enxergar "um gesto fundador que constrói uma filiação à qual os gramáticos brasileiros faráo referência sistemática", gesto por meio do qual "Júlio Ribeiro está afirmando uma nossa origem, a que resulta de uma ruptura no processo de colonizaçáo".

De acordo com Orlandi (2009, p. 175), Júlio Ribeiro "toma a palavra do gramático para constituir-se emblematicamente no primeiro autor de gramática no Brasil", pelo fato de ele "inaugurar uma discursividade e uma posição crítica face aos gramáticos portugueses na produção que faz do processo colonizador, agora não mais sob o governo português", no que se ressalta que, empiricamente, outros gramáticos poderiam ocupar esse lugar. Afirma Orlandi:

Júlio Ribeiro, ao recusar a tradição estabelecida por J. S. Barbosa e ao definir a gramática como "exposiçấo metódica dos fatos da linguagem" estabelece a 
ruptura que será mencionada por todos os gramáticos quando querem fundar uma filiação de gramática brasileira (ORLANDI, 2002, p. 131).

E ainda:

É preciso compreender que a forma da gramática traz em si o efeito-leitor de que deriva (ou determina) seu uso. Júlio Ribeiro é um parâmetro da ruptura com a tradiçáo gramatical portuguesa, parâmetro de citação do novo que irrompe no Brasil do século XIX (com sua independência, e a República) (ORLANDI, 2002, p. 149).

Nesse ponto, Guimarães (2004) destaca a importância da acusação de Júlio Ribeiro de que as antigas gramáticas portuguesas foram mais dissertaçôes de metafísica do que exposiçôes dos usos da língua, reaçáo interpretada como um distanciamento da influência direta de Portugal e busca de uma outra orientação teórica.

O nome de Júlio Ribeiro é frequentemente retomado nos estudos do projeto História das Ideias Linguísticas, inserindo-se, assim, sua presença de forma regular na história de estudos sobre o português do Brasil. Ao mesmo tempo, nos últimos anos, ampliou-se o conjunto de referências bibliográficas relativas a Júlio Ribeiro com o surgimento de artigos, dissertaçóes e teses que o tomam como objeto de análise.

\section{Critérios para a reiteraçáo de um lugar fundador para Júlio Ribeiro na história que se conta sobre as ideias linguísticas no Brasil}

Baseando-se frequentemente nas pesquisas da História das Ideias Linguísticas no Brasil, várias dissertaçóes e teses têm estudado a obra de Júlio Ribeiro nos últimos anos, desenhando uma imagem do autor como a referência primeira na construção de um modo brasileiro de fazer gramática no Brasil a partir do século XIX. Em suma, Júlio Ribeiro é tomado como um autor inovador, e mesmo fundador, por instalar algo novo no cenário de estudos linguísticos no país. O lugar de destaque reservado a Júlio Ribeiro na história que se conta sobre as ideias linguísticas no Brasil é fundamentado na defesa do seu protagonismo em pelo menos três pontos: 1. ter iniciado a gramática científica no Brasil, rompendo com os modelos anteriores da gramática geral e trabalhando com a gramática histórico-comparativa; 2 . ter sido o primeiro a explicitar as marcas próprias do português do Brasil; 3. ter 
sido a referência primeira dos outros gramáticos brasileiros.

Quando explicitamos a argumentação que constrói o fato de Júlio Ribeiro como o gramático responsável por introduzir a gramática histórico-comparativa no Brasil, vemos que essa introdução significa como a própria iniciação da gramática científica pelo rompimento com gramática geral, mas com a ressalva de que ele não se desvinculou completamente da tradição filosófica que dizia rejeitar, sendo Júlio Ribeiro reputado recorrentemente como um naturalista.

Vidal Neto (2010) afirma que "o papel de Ribeiro transcende ao ato de desbravar, pois foi o gramático que efetivamente instituiu novas teorias no cenário gramatical brasileiro, iniciando assim o chamado período científico" (VIDAL NETO, 2010, p. 24) e que Júlio Ribeiro "foi o responsável pela introdução, na rotina da gramática brasileira, dos métodos daqueles que adaptaram à análise da linguagem a doutrina positivista, de Augusto Comte" (VIDAL NETO, 2010, p. 25) e, portanto, "merece, de fato, o título de pioneiro e renovador de rotinas” (VIDAL NETO, 2010, p. 26).

Para Parreira (2011, p. 38), a Grammatica Portugueza "se constituye en la primera de su tradición que supone el fin del racionalismo para dar paso a un modelo gramatical basado en el concepto de codificación normativa, con cierto trasfondo de los supuestos positivistas e historicistas", acrescentando que ela "amplia las fuentes histórico-comparadas, al mismo tiempo que adopta nuevas teorías positivistas a partir de los autores portugueses y de los neogramáticos" (PARREIRA, 2011, p. 95). Parreira (2011, p. 175) defende ainda que Júlio Ribeiro "aplica al estudio del portugués los conocimientos más avanzados de su época”, particularmente "las investigaciones darwinistas sobre el origen y evolución de las especies", ressaltando, por fim, que "el pensamiento gramatical que aflora en Europa en este momento llega a Brasil a través de la Grammatica Portugueza y, como consecuencia de ello, desencadena una renovación y, por qué no decir, una revolución lingüística y gramatical" (PARREIRA, 2011, p. 186).

Retomando diretamente as afirmaçóes de Orlandi, Santos (2013, p. 66-67) vai enxergar na Grammatica Portugueza "um gesto de autoria em que o gramático anuncia um deslocamento da filiação filosófica portuguesa citando autores de outra perspectiva teórica, naturalista", ajuntando que a "gramática de Julio Ribeiro dá inicio à gramatizaçấo brasileira justamente por procurar romper com a tradição europeia da gramática filosófica e se filiar aos estudos histórico-comparativos", mas ressaltando haver "em sua gramática elementos dessa tradição filosófica que o autor rejeita”. De qualquer 
forma, Santos (2013, p. 43) trata a obra de Júlio Ribeiro como "a primeira gramática no Brasil que busca romper com a tradição de Portugal”.

Retomando também as afirmaçôes de Orlandi e Guimarães (2001), Emídio (2013, p. 9) toma a Grammatica Portugueza de Júlio Ribeiro como uma obra que "anunciava um novo posicionamento em relação aos estudos sobre a língua no Brasil, que se distanciavam da tradiçáo e buscavam novas influências". Ela defende ainda que as definiçôes que Júlio Ribeiro dá de gramática "legitimam o lugar de locutor-professor-brasileiro que é autorizado a definir e ressignificar o que seja a gramática, no Brasil, a partir da filiação a novas tendências, como é o método histórico-comparativo" (EMÍDIO, 2013, p. 122), concluindo que é na "ruptura com a gramática filosófica e com as tendências portuguesas gramaticais que reside o espaço de diferença proposto por Ribeiro" (EMÍDIO, 2013, p. 124).

Polachini (2013, p. 57) defende que Júlio Ribeiro é "o gramático que será responsável ao menos por reivindicar um novo posicionamento da gramaticografia brasileira", afirmando que nas últimas duas décadas do século XIX "haveria rupturas" em relação ao modelo da gramática geral francesa, "a primeira, permeada por uma forte retórica revolucionária, seria a de Ribeiro (1881), que seria seguida, posteriormente, pela de Maciel (1902 [1894])" (POLACHINI, 2013, p. 205).

A questão que aparece como principal quando Júlio Ribeiro é apontado como um autor fundador por ser considerado o primeiro a explicitar as marcas próprias do português do Brasil é a da legitimação da língua falada no Brasil com a marcação das diferenças em relação ao português falado em Portugal. Em alguns casos, a própria questão da normatividade é tomada como uma contribuição inédita de Júlio Ribeiro para a gramática no Brasil.

Vidal Neto (2010, p. 14) afirma que "Ribeiro foi o primeiro autor responsável por gramatizar o Português do Brasil”, primazia que significaria o "pioneirismo deste gramático em registrar a hiperlíngua brasileira", falando de um "olhar sociolinguístico" de Júlio Ribeiro, como se existisse uma antecipação dos estudos de sociolinguística no seu trabalho de registrar marcas linguísticas de sua época. Para Vidal Neto (2010, p. 110), por "fazer menção a usos típicos de nossa variante do Português, Ribeiro abre espaço para o início de uma longa discussão sobre a nacionalidade lingüística brasileira, levada a cabo intensamente, em território nacional, na primeira metade do século XX".

Parreira (2011, p. 18) afirma que a gramática de Júlio Ribeiro "reúne los fundamentos de la tradición anterior, proporciona un modelo descrip- 
tivo del idioma contemporáneo y aporta conocimientos históricos y contrastivos del portugués en sus diferentes variedades", de forma que "esta obra constituye la primera propuesta cabal de una gramática normativa del portugués”. Parreira (2011, p. 171) náo deixa de reconhecer, assim, da parte de Júlio Ribeiro, "nuevas atribuciones a la gramática que aún no habían sido consideradas en esta tradición", explicando que "Ribeiro pone de relieve la función comunicativa y, especialmente, social de la lengua". Por fim, Parreira (2011, p. 387) marca também uma importância da Grammatica Portugueza na tradição gramatical brasileira pelo recurso a outras línguas românicas e ao próprio latim para a descrição do português, ressaltando que "esta es la primera vez en la tradición brasileña que se explican usos sintácticos del portugués por medio de la comparación entre las lenguas modernas, pero sin tomar en consideración preferente las diferencias con el latín y el francés".

Sempre retomando as afirmaçóes de Orlandi, Santos (2013, p. 67) considera "a importância dos estudos de Julio Ribeiro para a legitimidade do falante do português do Brasil", argumentando que ele "vai instituindo a norma de uma língua falada no Brasil, que se marca diferente da língua imposta pelos portugueses" (SANTOS, 2013, p. 83). "Tendo como projeto deslocar o saber metalinguístico de Portugal para o Brasil, deu visibilidade a um saber legítimo pertencente à sociedade brasileira como um todo", resume Santos (2013, p. 129) sobre a contribuição "fundadora e continuadora" de Júlio Ribeiro na "construção do saber metalinguístico e da constituição da língua nacional” no Brasil.

Polachini (2013, p. 88) marca que Júlio Ribeiro "é certamente o autor, dentre os seis analisados, que cita elementos declarados específicos do português brasileiro com mais freqüência”. Ela refere-se a Morais Silva, Coruja, Sotero dos Reis, Freire da Silva e Maciel. Polachini (2013, p. 200) afirma que haveria a partir da gramática de Júlio Ribeiro "um encaminhamento para o Programa Descritivista, visto que tanto Maciel quanto Ribeiro buscam os fatos e normas da língua, e já não analisam a expressão do pensamento, além de suas análises focarem-se frequentemente na comparação entre línguas".

Os argumentos que tomam Júlio Ribeiro como o grande nome do processo de gramatização brasileira o descrevem como um gramático que abriu um novo caminho nos estudos sobre a língua no Brasil. Em suma, Júlio Ribeiro é exposto como um marco, uma referência sistemática, um autor que conquistou seguidores, que deixou um legado. Esses gestos de interpretação são produzidos quase exclusivamente sobre a gramática de 1881, 
de modo que, se Júlio Ribeiro é tomado como um autor fundador por ser a referência primeira na gramatização brasileira, ele o é enquanto autor da Grammatica Portugueza.

Novamente retomando as afirmações de Orlandi, Santos (2013, p. 34) afirma que Júlio Ribeiro "ocupa o lugar fundador da gramática no Brasil". A Grammatica Portugueza e os dicionários do português do Brasil publicados na segunda metade do século XIX são tomados como "publicaçôes pioneiras" que "fundam no país uma memória do conhecimento científico sobre a língua que se falava no Brasil, como forma de legitimá-la e de reafirmá-la como unidade de um Estado nacional independente de Portugal" (SANTOS, 2013, p. 31). A ideia de Júlio Ribeiro como um marco na história da gramatização brasileira pode ser percebida claramente quando Santos (2013, p. 34) narra que "ao longo do século XIX, trabalhos importantes para o processo de gramatização, anteriores e posteriores à gramática de Júlio Ribeiro, foram publicados no Brasil". Na mesma linha, a partir das mesmas referências, Emídio (2013, p. 15) define a gramática de Júlio Ribeiro como "um instrumento linguístico extremamente relevante para o acontecimento da gramatização brasileira", ressaltando que ela foi "aclamada pela sociedade letrada da época".

Gurgel (2008, p. 53) considera que

\begin{abstract}
as gramáticas originalmente brasileiras surgiram a partir do ano de 1880 porque foi somente nesse momento que um 'exemplar' brasileiro surgiu para orientar o grupo de profissionais ligados aos estudos da linguagem naquele período: a Grammatica Portugueza de Júlio Ribeiro.
\end{abstract}

Nesse sentido, a autora fala em "liderança intelectual de Júlio Ribeiro", argumentando que a retórica de ruptura teórica com a tradição filosófica encontrada nas introduçóes dos textos gramaticais do período comprova que "o esforço que Júlio Ribeiro fez em promover uma nova visão aos estudos da linguagem surtiu efeito" (GURGEL, 2008, p. 55). Gurgel (2008, p. 58-59) chega ao ponto de defender que a "obra de Júlio Ribeiro náo foi, certamente, a única fonte a ser seguida pela geraçáo mas, sem dúvida, foi o modelo de descrição de língua que inspirou também a elaboração dos programas de Fausto Barreto", sendo esses dois elementos entendidos como "duas das principais causas da gramaticização brasileira" (GURGEL, 2008, p. 62).

Vidal Neto (2010, p. 28) reforça que Júlio Ribeiro é "um gramático 
que rompeu modelos", destacando "o quanto Ribeiro foi representativo no cenário gramatical brasileiro, pois mesmo para os que não o seguiram totalmente, ele serviu de referência". Por essa razão, Vidal Neto (2010, p. 53) contempla a "gramatização do Português do Brasil" como um "processo que teve início apenas com a Gramática Histórico Comparada, com a publicação da Grammatica, de Ribeiro, em 1881".

Polachini (2013) posiciona Júlio Ribeiro num movimento de rupturas e continuidades em relação a Morais Silva, Coruja, Sotero dos Reis, Freire da Silva e Maciel, decretando náo haver algo que determine uma ruptura total ou uma continuidade absoluta no tratamento de certas questôes da sintaxe em gramáticas brasileiras do século XIX (sentença, concordância, regência, sintaxe figurada e vícios), mas explicando que uma:

\begin{abstract}
ruptura maior, entretanto, teria ocorrido entre Ribeiro e todos os gramáticos anteriores, porque mesmo temas que ganhavam continuidade, como a noção de "sentença" e a noção de "complemento" foram subvertidos em Ribeiro, entretanto, existe ainda a continuidade, como a concepção de "verbo substantivo" que resulta na "cópula”. (POLACHINI, 2013, p. 203).
\end{abstract}

É também num movimento de rupturas e continuidades que Parreira (2011) posiciona Júlio Ribeiro no estudo que faz do tratamento das partes da gramática, das classes de palavras, da sintaxe e da semiologia em gramáticas brasileiras no século XIX. Essas análises específicas parecem jogar contra o absolutismo da posição de que Júlio Ribeiro é uma referência incontornável na gramatização brasileira, no entanto, mesmo esses trabalhos não deixam de destacar uma importância central da obra de Júlio Ribeiro na gramatização brasileira.

\title{
Autoprojeção de Júlio Ribeiro numa posiçáo desbravadora nos estudos gramaticais e linguísticos no Brasil e no cenário internacional
}

Júlio Ribeiro se póe frequentemente em primeiro plano nos seus textos, realizando assim de modo muito personalista aquela estratégia de qualquer autor em criar para si mesmo um espaço de representação em sua obra. Sem escapar ao procedimento de dizer de si através do outro, para parafrasear a expressão de Medeiros (2003), é com apontamento do outro que Júlio Ribeiro marca frequentemente um espaço da falta no cenário de reflexão sobre a linguagem no Brasil, retornando sobre si mesmo para descrever a su- 
peração dessa falta, assumindo voluntariamente uma posição desbravadora no debate linguístico no Brasil.

Vejamos o jogo de representação de Júlio Ribeiro inicialmente na polêmica com o gramático maranhense Augusto Freire da Silva. A preferência de Júlio Ribeiro $(1887$, p. 23) pelo termo sentença em detrimento do termo período é tomada pelo próprio autor como uma inovação, marcando, portanto, uma contribuição sua no cenário dos estudos gramaticais no Brasil: "Em meu ultimo artigo usei do termo sentença em vez do termo periodo. Foi uma innovaçáo". No caso específico do uso do termo sentença, a justificativa se dá pelo seguimento das gramáticas inglesas, como se houvesse aí, portanto, uma outra inovaçáo da sua parte, a observaçáo dos estudos gramaticais ingleses, a disponibilização de novas referências teóricas:

\begin{abstract}
Ora innovaçóes desnecessarias revelam apenas toleima por parte de quem as faz. Preciso é, pois, justificar-me. As grammaticas inglezas dão o nome de sentença á coordenação de palavras, formando sentido completo: só fallam de periodo como ponto final. Que temos nós com as grammáticas inglezas? Temos muito, temos tudo, respondo. Os inglezes sabem fazer as cousas, pensam, meditam, têm bom senso. E de bom senso é que nós precisamos. Tomel-os, quanto possivel, dos mestres inglezas (RIBEIRO, 1887, p. 23-24).
\end{abstract}

Fica claro que, ligando-se às gramáticas inglesas, a inovaçáo de que se autoproclama Júlio Ribeiro é em relação ao conjunto global dos estudos do português. Júlio Ribeiro apresenta-se como um expositor fiel da linguística:

Poderia eu ainda citar por ediçóes, por paginas, por linhas, a Bréal, a Max Muller, a Whitney, a Hovelacque, a Bopp, a Bastin, a Diez, a Pacheco Junior, a muitos outros; porém não o faço: creio estar provado que o sr. dr. Augusto Freire da Silva nâo me atacou a mim, espositor indouto mais fiel, porém sim que, em nome da rotina e do passado, atacou a sciencia e o presente" (RIBEIRO, 1887, p. 81).

Temos aí, portanto, uma série de nomes de autores significados enquanto nomes de linguistas, e como tais, associados à ciência e ao presente, em oposiçáo à rotina e ao passado, elementos tidos como próprios dos gramáticos metafísicos. Nesse esquema, Júlio Ribeiro retrata-se como um expositor atualizado da ciência linguística.

$\mathrm{Na}$ avaliação de Júlio Ribeiro (1887, p. 85), tudo o que ele vem apresentando sobre a etimologia e a morfologia são teorias seguidas por todos os 
linguistas modernos: "Estas theorias são maes ou menos as seguidas por Max Müller, por Whitney, por Coelho, por Guardia e Wierzeyski, por Bréal, por Pacheco Junior, por todos os linguistas modernos". Em mais uma ocasião, Júlio Ribeiro apresenta-se como seguidor e divulgador de teorias linguísticas modernas, teorias científicas que encontrariam consenso entre nomes como Max Müller, Whitney, Coelho, Guardia e Wierzeyski, Bréal e Pacheco Junior.

Na polêmica com Augusto Freire da Silva, é falando justamente em consenso que Júlio Ribeiro (1887, p. 85) afirma que "o que impede o vocabulo Etymologia de desapparecer da Linguistica, é o ter elle em seu favor o consenso universal deste século", emendando que "Lexeologia seria termo muito mais proprio". Assim, Júlio Ribeiro coloca-se como aquele que não partilha o consenso universal do seu século em torno do emprego de um termo gramatical, a etimologia, o que sugere que ele estaria, portanto, à frente do seu tempo, do seu século, livre dos consensos universais.

Se em certos momentos Júlio Ribeiro $(1887$, p. 86) póe-se na contracorrente dos consensos universais, ele mostra-se, em outros, como um autor que anda com a moda, como alguém que acompanhou a tendência da terminologia da ciência moderna, colocando-se ao lado de figuras como Hæckel: "S. s. sabe que a terminologia scientifica hodierna é toda tirada do Grego: eu andei com a moda, fiz como Hæckel, pilhei da cozinha grega os meus adubos".

Quando nega a possibilidade de falar em princípio particular e a confusão entre princípio e fato, Júlio Ribeiro, mais uma vez, coloca-se na posição de quem adere e defende os ensinamentos da ciência moderna, reservando para seu adversário o tempo do passado e o lugar da não ciência, representados pelas teorias escolástico-metafísicas:

Em abono dos rudimentos da sciencia hodierna, que o sr. dr. Augusto Freire da Silva innocentemente ignora, poderia eu fazer mostra de erudição, citando trechos e trechos de J. Muller, de Max Muller, de Burgraff, de Whitney, de Hovelacque, de Broca, de Letourneau, de Bréal, de Topinard, de Hæckel, de Darwin, de Tylor, de Lubbock, de Gama Rosa, de muitos outros.

E não citaria de outiva.

Relembraria apenas as continuas leituras, a que me impelle o desejo ardente que tenho de diminuir o mais possivel a minha profunda ignorancia.

Meu fim, porém, não é provar que tenho lido muito: com tal prova em eu lucraria, nem lucraria a humanidade.

Meu fim é mostrar que o ensino official, cathedratico, privilegiado já não 
póde mais, sem estribar-se na sciencia, oppôr-se ao tentamen dos que acompanham o século, dos que querem ser úteis á causa do progresso, que é a causa da humanidade.

Ataquei theorias escolastico-metaphysicas, theorias adoptadas e peioradas por Sotero dos Reis, e sahiu-me pela frente o sr. dr. Augusto Freire da Silva, Professor Cathedratico de Portuguez na Faculdade de S. Paulo (RIBEIRO, 1887, p. 91-92).

Uma vez mais, vemos aproximadamente os mesmos nomes significados enquanto cientistas modernos. Uma vez mais, Júlio Ribeiro coloca-se em companhia desses cientistas modernos. Uma vez mais, a linguística enquanto uma ciência moderna é colocada em oposição a teorias metafísicas.

No início de seus Traços Geraes de Linguistica, no aviso ao leitor, Júlio Ribeiro apresenta-se como um autor de linguística que segue e reproduz investigaçóes de uma série de outros autores, em sua ampla maioria estrangeiros, significados eles mesmos enquanto autores de linguística. No espaço do Brasil, Júlio Ribeiro assumiria então a importância de introduzir conhecimentos linguísticos de fora do país. No entanto, ele apresenta-se também como um autor que faz novas investigaçóes. Assim, por trazer contribuiçóes para a reflexão linguística em geral, Júlio Ribeiro teria uma importância mundial nos estudos linguísticos:

\footnotetext{
Quasi com o mesmo direito com que nos rotulos de vinhos preciosos figura a firma dos engarrafadores, vai o meu nome na frente deste livrinho. Verdade é que são minhas algumas das investigaçōes nelle exaradas, que é minha a exposição ; a maior e melhor parte, porém, nâo me pertence; pertence aos mestres cujos ensinamentos repeti, cujas palavras por vezes trasladei litteralmente. Tambem o unico fim que tenho em vista com esta publicação é despertar no publico estudioso uma curiosidade salutar, que póde ser amplamente satisfeita em Comte, Spencer, Darwin, Tylor, Hæckel, Broca, Letourneau, Topinard, Luys, Ferrière, Zaborowski, Bopp, Schleicher, Grimm, Max Müller, Whitney, Renan, Diez, Brachet, Bréal, Lefèvre, Theophito Braga, Adolpho Coelho, Pacheco Junior, e em cem outros mestres de Linguistica e das sciencias que lhe são correlatas. Que o livrinho vem encher uma lacuna, não Ha negá-lo: entre nós ainda ha muita gente de bom saber a acreditar piamente que em materias de philologia e de linguística disse Sotero dos Reis a ultima palavra (RIBEIRO, 1880, p. 10).
}

Com o objetivo manifesto de preencher uma lacuna na área de publicaçôes sobre linguística no Brasil e criticando fortemente o trabalho do gramático brasileiro Francisco Sotero dos Reis por estar ligado à tradiçáa da 
gramática geral e filosófica, o livro de Júlio Ribeiro procura filiar-se aos estudos de figuras já várias vezes significadas em sua obra como autoridades no fazer científico sobre a linguagem e as línguas. É Júlio Ribeiro, segundo sua própria avaliação, quem vai, portanto, preencher um lugar vazio na reflexão sobre a linguagem no Brasil, pela publicação de um livro de linguística, e quem vai aportar novas investigaçóes para a pesquisa linguística no mundo.

Na sua Grammatica Portugueza, Júlio Ribeiro continua afirmando-se como um autor que segue os passos da linguística, como um gramático que segue o estudo da gramática histórico-comparativa:

\begin{abstract}
Os factos de uma lingua qualquer só podem ser cabalmente elucidados pelo estudo historico comparativo da grammatica dessa lingua. As explicaçóes metaphysicas, mais ou menos subtis, mais ou menos engenhosas, nunca satisfazem. Os meios que emprega o Latim, que empregam as linguas romanicas para indicar de modo abstracto a pluralidade indeterminada do agente de um verbo, têm servido do thema a milhares de divagaçóes tăo prolixas quanto abstrusas, táo requintadas quanto estereis. Analysar esses meios á luz do estudo historico comparativo das grammaticas romanicas e da latina, eis o fim que levo em vista. E não me apresento como exhibindo novidades: sigo apenas os passos dos srs. C. Waldbach e Adolpho Coelho, de Diez e Bopp, de todos os mestres de philologia e linguistica (RIBEIRO, 1881, p. 286).
\end{abstract}

Uma frase de Duarte Nunes de Leão utilizada por Júlio Ribeiro como epígrafe em sua gramática não é menos esclarecedora sobre a posição de inovação em que se ele coloca muitas vezes: "Tentei ensinar aos meus naturaes o que eu de outrem não pude aprender”. Dessa forma, se Júlio Ribeiro diz seguir os mestres de filologia e de linguística, esse seguimento funcionaria como uma inovação dentro do cenário de reflexão sobre a linguagem no Brasil, pela introdução de estudos que não teriam sido realizados até então no país e que só teriam passado a ser realizados por obra do próprio Júlio Ribeiro, um modo de dizer que marca um antes e um depois de sua atuação no trabalho linguístico no país. Assim, a repetição do que se dizia sobre linguagem fora do Brasil é, dentro do país, uma inovaçáo, operada, sempre segundo Júlio Ribeiro, por ele próprio. No cenário internacional, como já vimos, a contribuição de que fala Júlio Ribeiro estaria em trazer novas investigaçôes à pesquisa linguística. Na gramática sobretudo, é na oposição às antigas gramáticas portuguesas que Júlio Ribeiro apresenta o valor de seu próprio trabalho: 
do que exposiçóes dos usos da lingua.

Para afastar-me da trilha batida, para expôr com clareza as leis deduzidas dos factos e do fallar vernaculo, náo me poupei a trabalhos (RIBEIRO, 1911, p. I).

Colocando-se no caminho oposto ao da metafísica, que caracterizaria as antigas gramáticas portuguesas, Júlio Ribeiro apresenta seu trabalho de análise como a exposição de fatos deduzidos do falar vernáculo. Os nomes que aparecem como guia desse trabalho são os de Whitney, Becker, Mason, Bain, Holmes, Adolfo Coelho e Teófilo Braga:

\footnotetext{
Abandonei por abstractas e vagas as definiçóes que eu tomára de Burgraff: preferi amoldar-me ás de Whitney, mais concretas e mais claras. O systema de syntaxe é o systema germanico de Becker, modificado e introduzido na Inglaterra por C. P. Mason, e adoptado por Whitney, por Bain, por Holmes, por todas as summidades da grammaticographia saxonia.

O meu modo de expôr, a ordem que segui em distribuir as materias é de Bain. Cumpre notar que, ao dar á luz em 1881 a primeira ediçăo desta grammatica, eu ainda náo tinha visto a "A Higher English Grammar ».

Folgo de que, sem prévio accordo, eu tenha no campo do pensamento caminhando a par de espirito tấo elevado. Que se concluirá de ter a minha obscuridade achado sem guia o mesmo caminho seguido pelo eminente logico inglez?

E' que, sendo identico os processos que empregamos na distribuiçấo dos factos glotticos e na maneira de encaral-os, identico foi o resultado

$[\ldots]$

Ocioso seria confessar que muito devo a Paulino de Souza, a Theophilo Braga e a outros grammaticographos portuguezes. Quem for versado em estudos de lingua vernacula, facilmente verá de quanto me valeram esses mestres. Pelo que respeita a Adolpho Coelho, pergunto: quem poderá escrever hoje sobre philologia portugueza, sem tomal-o por guia, sem se ver forçado a copial-o a cada passo? (RIBEIRO, 1911, p. II-III)
}

Júlio Ribeiro coloca-se em proeminência em relação ao Programa de Português para os Exames Preparatórios, cuja elaboração, como mostram Orlandi e Guimarães (2001), representou um acontecimento determinante na gramatização brasileira. Como mostra Guimarães (2014), o estabelecimento do Programa de Português é catalizador da gramatização brasileira, mudando, na medida em que abriu a porta para o aparecimento de novas gramáticas, o ensino da língua e criando uma pressão sobre o conjunto de estabelecimentos de ensino da época, o que nos permite argumentar contra 
a ideia de que um único teria sido o primeiro a iniciar esse processo de produção de instrumentos linguísticos no Brasil. Júlio Ribeiro, no entanto, coloca-se em anterioridade aos Exames, argumentando que sua Grammatica Portugueza já havia realizado tudo aquilo previsto pelo Programa bem antes de ele ser elaborado por Fausto Barreto.

De acordo com a avaliação que Júlio Ribeiro ([1887] 2007, p. 93) faz do Programa num artigo publicado em 1887 no seu próprio jornal A Procellaria, ele seria "organizado scientificamente, sobre as bases largas, solidas, da sciencia da linguagem", sem "nada de superfetaçóes escholasticas, nada de metaphysica medieval”, enaltecendo as divisóes da gramática em lexeologia e sintaxe e estimando, num elogio da completude, que ele não deixaria de fora nenhum ponto gramatical, pois "nada se olvida no programma, de tudo se trata".

No fim das contas, a valorização que Júlio Ribeiro faz do Programa de Português é uma valorização do seu próprio trabalho, pois ele se representa como antecessor do Exame e também como o autor da única gramática que reune as condiçôes de preparar um aluno não apenas para a prova de português, mas de todas as línguas ensinadas oficialmente no Brasil:

\begin{abstract}
Si foramos vaidoso, era esta a hora de rejubilar: o programma de Portuguez, bem como os de todas as outras linguas que se ensinam officialmente no Brasil, está de accordo exacto, perfeito com os principios da grammatica scientifica, que, em 1881, tivemos a ousadia de arrojar á publicidade.

Hoje abundam em Portuguez monographias linguisticas valiossimas; temos a primeira parte da monumental grammatica historica de Pacheco Junior; Adolpho Coelho, Leite de Vasconcellos, João Ribeiro, Fausto Barreto, Lameira de Andrade brilham como astros de primeira grandeza no céo da nossa philologia: mas, ainda assim, é a nossa Grammatica a unica grammatica por onde se possa preparar um alumno para enfrentar com o actual programma de exames (RIBEIRO, [1887] 2007, p. 93-94).
\end{abstract}

Na verdade, para Júlio Ribeiro, não é a Grammatica Portugueza que está de acordo com o Programa de Português, mas o Programa de Português que está de acordo com a Grammatica Portugueza. Assim, se o Programa é elogiado por Júlio Ribeiro por estar organizado cientificamente sobre as bases da ciência da linguagem, isso se daria pelo fato de ele estar de acordo com os princípios de sua própria gramática, uma gramática científica segundo sua descriçáo. Seguindo esse modo de pensar, se o Programa de Português é louvado por dividir a gramática em lexeologia em sintaxe, por superar a 
escolástica e a metafísica e por abordar todas as questóes sobre a linguagem, é a própria gramática de Júlio Ribeiro quem é engrandecida por essas realizaçôes na medida em que ela é colocada como guia do Programa de Português.

Em suma, Júlio Ribeiro expóe sua gramática como uma categoria à parte em sua época, mesmo como um divisor de águas. De um lado, as gramáticas de Pacheco Junior, Adolfo Coelho, Leite de Vasconcelos, João Ribeiro, Fausto Barreto, Lameira de Andrade, valiosíssimas monografias linguísticas em português. Do outro, isoladamente, a Grammatica Portugueza, uma gramática científica, única capaz de preparar os alunos para as provas de português e de todas as outras línguas ensinadas oficialmente no Brasil. Os nomes dos portugueses Adolfo Coelho e Leite de Vasconcelos mostram que essa singularidade reivindicada por Júlio Ribeiro não se dá apenas em relação aos trabalhos dos brasileiros, mas em relação ao conjunto geral de estudos sobre o português, em relação a brasileiros e portugueses.

No seu romance $A$ Carne, num apurado jogo de projeçóes, no qual personagens criados segundo um modelo de excelência do conhecimento científico falam positivamente do seu próprio criador, Júlio Ribeiro apresenta-se como separado da figura tradicional do gramático. É no trecho de um fragmento de carta trocada pelo casal de amantes do romance que Júlio Ribeiro projeta uma imagem de si:

\footnotetext{
Encomenda de Júlio Ribeiro, um gramático que se pode parecer com tudo menos um gramático: não usa simonte, nem lenço de Alcobaça, nem pince-nez, nem sequer cartola. Gosta de porcelanas, de marfins, de bronzes artísticos, de moedas antigas. Tem, ao que me dizem, uma qualidade adorável, um verdadeiro título de benemerência - nunca fala, nunca disserta sobre coisas de gramático (RIBEIRO, [1888] 2002, p. 270).
}

Lenita, a remetente, é descrita como uma moça que teve "ótimos professores de línguas e de ciências; estudou o italiano, o alemão, o inglês, o latim, o grego; fez cursos muito completos de matemáticas, de ciências físicas, e não se conservou estranha às mais complexas ciências sociológicas". O destinatário, Barbosa, é apresentado como alguém que "fizera centenas de dissecaçôes anatômicas" e "aprofundara estudos de embriogenia", enfim, um "homem muito instruído", que "fala umas poucas línguas, e conhece bastantes ciências".

Entre passeios campestres e atos carnais, Lenita e Barbosa trocam liçôes sobre ornitologia, botânica, climatologia, geologia, indústria, agricultura, física, química, fisiologia, glótica e teorias transformistas, citando nomes 
como Van Helmont, Martius, Darwin e Haeckel. São personagens com essa formação que falam positivamente de Júlio Ribeiro como um autor destacado, de "qualidade adorável". Nesse esquema de representação, é como se Júlio Ribeiro realizasse, pelo menos que corresponde ao conhecimento linguístico, o nível de preparo científico que ele elabora e exige das mais diferentes instâncias da sociedade brasileira.

Júlio Ribeiro posiciona-se numa posição proeminente na história dos estudos linguísticos, brasileiros e mundiais, por açóes como a preferência e introdução de termos gramaticais, a disponibilizaçáo de novas referências teóricas e superação da escolástica e da metafísica, a publicação de uma obra de linguística e a escrita de uma gramática científica. Em suma, Júlio Ribeiro coloca-se na posição de fazer o que ainda não teria sido feito e de atualizar aquilo que estaria ainda parado no passado. Assim, Júlio Ribeiro náo se representa apenas como seguidor e divulgador de teorias linguísticas modernas, afirmando-se como um autor que segue os passos da linguística e como um gramático que segue o estudo da gramática histórico-comparativa, com suas escolhas sendo justificadas como orientadas por critérios científicos, mas também como um portador de novas investigaçóes para a pesquisa linguística no mundo e como alguém que estaria à frente do seu tempo.

\section{Júlio Ribeiro, autor fundador?}

Se um dos critérios para considerar Júlio Ribeiro como um autor fundador é ter iniciado a gramática científica no Brasil pela introdução da gramática histórico-comparativa no país, rompendo com os modelos anteriores da gramática geral, é preciso argumentar que, antes de assumir a defesa da cientificidade dos estudos histórico-comparativos, é justamente o caráter do que é científico que está em jogo na produção de gramáticas brasileiras na virada do século XIX para o XX, pois, como mostramos em outro trabalho (AQUINO, 2016, 2017), há autores da época que reclamam a cientificidade da gramática geral. Por outro lado, a relação de Júlio Ribeiro com a gramática histórica e comparada não se dá sem tensóes, sem interpretaçôes particulares. Ele apresenta uma explicação não ortodoxa de alguns elementos centrais do comparativismo, estabelecendo como critérios para a mudança linguística "os costumes", "as relaçôes exteriores", "as ciências", "a indústria", "o gênio literário", "a instrução pública” e "o trabalho intelectual”, critérios que ressignificam, portanto, a gramática histórica e comparada, que, principalmente na versão mais extrema dos neogramáticos, desconsidera qualquer 
elemento extralinguístico e toma unicamente as leis fonéticas como causas da mudança linguística (AQUINO, 2012, 2016, 2018). Assim, se é verdade, com se marca frequentemente, que Júlio Ribeiro é afetado pela mesma tradiçáo que ele procura negar, é igualmente verdade que ele ressignifica a tradição que ele diz reivindicar, a da gramática histórico-comparativa, tomando em conta fatores de ordem social, econômica, política e cultural.

São várias as descriçôes do português falado no Brasil feitas pelos gramáticos brasileiros na virada para o século XX, autores que levantam frequentemente os mesmos fenômenos descritos por Júlio Ribeiro. Antes de colocar a questão de saber se o início dessas descriçóes se fez a partir e através de Júlio Ribeiro, nos parece mais coerente pensar que são fenômenos observados na medida em que estáo amplamente em voga na época, a ponto de serem percebidos como diferenças em relaçáo ao português europeu. Os gramáticos brasileiros não são surdos a formas e construções que, como mostra o trabalho de Tarallo (1996), são sintomáticas das mudanças em curso do português no Brasil, mesmo que muitas vezes tomadas como erro. Em suma, se o critério para tomar Júlio Ribeiro como um autor fundador no processo de gramatizaçáo brasileira é o fato de ter sido o primeiro a registrar as marcas próprias do português do Brasil, cabe dizer que Pinto (1978) demonstra que já na década de 1820 é possível assistir às primeiras manifestaçôes sobre a natureza do português no Brasil, quando o Visconde de Pedra Branca faz menção ao "idioma brasileiro" e aponta diferenças lexicais de sentido entre o português do Brasil e o português de Portugal. Nesse sentido, Orlandi e Guimarães (2001, p. 30) afirmam que a "caracterização do português do Brasil pelo léxico já é perceptível desde a primeira metade do século XIX".

Se outro critério para considerar Júlio Ribeiro como um autor fundador no processo de gramatização brasileira é o fato de ele ter assumido a posição de referência incontornável para falar sobre a língua no Brasil, salientamos que seu nome é relativamente pouco mencionado no horizonte de retrospecção da gramatização brasileira. $\mathrm{Na}$ verdade, como demonstramos em outros trabalhos (AQUINO, 2016, 2017), quando analisamos o lugar de Júlio Ribeiro no conjunto dos trabalhos brasileiros publicados desde o aparecimento de sua Grammatica Portugueza, em 1881, até a instituição da Norma Gramatical Brasileira em 1959, percebemos, primeiro, que não havia consenso quanto ao seu peso, e, segundo, que a maior parte da sua produção foi completamente apagada. No entanto, seu nome sempre está presente quando se faz uma periodizaçáo ou história dos estudos da gramática e do português no Brasil, sendo colocado na posiçấo de marco pelos 
autores Ernesto Carneiro Ribeiro, Maximino Maciel, Eduardo Carlos Pereira, Antenor Nascentes, José Rizzo e Francisco da Silveira Bueno. Por essa razão, relevando como são controversos os discursos de fundação, podemos afirmar uma contradição entre um apagamento de Júlio Ribeiro como referência para a realização de análises gramaticais e linguísticas e um discurso historiográfico que o coloca a cada instante em primeiro lugar na história dos estudos gramaticais e linguísticos no Brasil, um discurso que parece migrar de autor para autor, às vezes de forma direta, sob forma de citação, e que, muitas vezes, parte dos dizeres do próprio Júlio Ribeiro, como se houvesse uma adesão ao seu próprio discurso de autorreconhecimento como alguém que introduz o novo numa história dos estudos linguísticos no Brasil (AQUINO, 2016, 2017).

Em síntese, os critérios para tomar Júlio Ribeiro como autor fundador da gramatização brasileira do português não resistam à prova dos fatos, por assim dizer, pois ele nunca foi a referência primeira, sistemática ou incontornável de todos os outros gramáticos brasileiros, sejam eles contemporâneos ou posteriores a ele, tampouco o primeiro a apontar as marcas características do português do Brasil, muito menos o primeiro a levantar o estandarte da cientificidade do trabalho gramatical, sendo, finalmente, uma simplificação afirmar que ele iniciou a gramática científica no Brasil, rompendo com os modelos da gramática geral e aderindo completamente à gramática histórico-comparativa, uma vez que a relação do autor com essas teorias se estabelece com conflitos e ressignificaçóes. No entanto, a imagem que fica de Júlio Ribeiro, pela repetição de certos dizeres e na esteira das palavras do próprio autor sobre si, é a de um marco inaugural na história das ideias linguísticas no Brasil. Assim, é pela repetição e não pela validade dos argumentos que tem sido continuamente reafirmado, como mito de origem, o lugar fundador de Julio Ribeiro na história dos estudos gramaticais e linguísticos no Brasil. Uma "linha de demarcação", sem dúvida, para usar a expressão de Pêcheux e Balibar (1969)! Um "ponto de não-retorno"?

\section{Referências}

AQUINO, J. E. Os nomes da língua na Grammatica Portugueza de Júlio Ribeiro. Língua e Instrumentos Linguísticos, Campinas, n. 30, p. 71-99, 2012. 
. Júlio Ribeiro na história das ideias linguísticas no Brasil. 2016.

354 p. Tese (doutorado em Linguística)-Instituto de Estudos da Linguagem, Universidade Estadual de Campinas, Campinas, SP, Université Sorbonne Nouvelle - Paris III, Paris, 2016.

- Júlio Ribeiro no horizonte de retrospecto da gramatização brasileira. Confluência, Rio de Janeiro, n. 52, p. 147-179, 2017.

A primeira obra de linguística produzida no Brasil: Traços Geraes de Linguistica (1880) de Júlio Ribeiro. Domínios de Lingu@gem, Uberlândia, n. 12, p. 218-254, 2018.

EMÍDIO, C. L. Júlio Ribeiro e a fundaçáo de um espaço de escrita nacional. 2013. 166 p. Dissertação (Mestrado em Estudos da Linguagem)Universidade Estadual de Londrina, Londrina, PR, 2013.

GUIMARÁES, E. Instruments linguistiques et la langue nationale : un événement au Brésil au XIXe siècle. In: ARCHAIMBAULT, S.; FOURNIER, J-M.; RABY, V. (Éds.). Penser l'histoire des savoirs linguistiques : hommage à Sylvain Auroux. Lyon : ENS Éditions, 2014. p. 465-477.

. História da semântica: sujeito, sentido e gramática no Brasil. São Paulo: Pontes, 2004.

. Sinopses dos estudos do português no Brasil. Relatos, Campinas, n. 1, 1994. Disponível em: <http://www.unicamp.br/iel/hil/publica/relatos_01.html\#sinopse>. Acesso em: 24 out. 2016.

GURGEL, S. O período dos estudos linguísticos brasileiros dito científico na questão da colocaçáo pronominal (1880-1920). 2008, 144 p. Dissertação (Mestrado em Semiótica e Linguística Geral) - FFLCH, Universidade de São Paulo, São Paulo, SP, 2008. 
MEDEIROS, V. Dizer a si através do outro: do heterogêneo no identitário brasileiro. 2003. 275 p. Tese (Doutorado em Linguística)- Instituto de Letras, Universidade Federal Fluminense, Niterói, RJ, 2003.

ORLANDI, E. P. Língua brasileira e outras histórias: discurso sobre a língua e ensino no Brasil. Campinas: RG, 2009.

. Língua e conhecimento linguístico: para uma história das ideias linguísticas no Brasil. São Paulo: Cortez, 2002.

; GUIMARÃES, E. Formação de um Espaço de Produção Linguística: a gramática no Brasil. In: Orlandi, E. P. (Org.) História das ideias linguísticas: construção do saber metalinguístico e constituição da língua nacional. Mato Grosso: Pontes, 2001. p. 21-38.

PARREIRA, A. D. Contribución a la historia de la gramática brasileña del siglo XIX. 2011. 477 p. Tese (Doutorado em Filologia)- Faculdade de Filología, Universidad de Salamanca, Salamanca, 2011.

PÊCHEUX, M.; BALIBAR, E. Definiçôes. In: PÊCHEUX, M.; FICHANT, M. Sobre a história das ciências. São Paulo: Mandacaru, 1969. p. 11-16.

POLACHINI, B. S. O tratamento da sintaxe em gramáticas brasileiros do século XIX: estudo historiográfico. 2013. 221 p. Dissertação (Mestrado em Linguística)- FFLCH, Universidade de São Paulo, São Paulo, SP, 2013.

RIBEIRO, J. Traços geraes de linguistica. São Paulo: Livraria Popular de Abilio A.S. Marques, 1880.

Grammatica Portugueza. São Paulo: Jorge Seckler, 1881.

Grammatica Portugueza. 10. ed. São Paulo: Livraria Francisco Alves, 1911. 
. Questáo grammatical. São Paulo: J. Lousada \& Comp., 1887.

. Cartas sertanejas. Procellarias. São Paulo, SP: Imprensa Oficial: FUNDAP, [1887] 2007.

. A carne. São Paulo: Ateliê Editorial, [1888] 2002.

SANTOS, G. A. Os efeitos de sentidos da formulaçáo das regras e os acréscimos nas gramáticas de Julio Ribeiro, Said Ali e Evanildo Bechara. 2013. 140 p. Tese (Doutorado em Linguística)-Instituto de Estudos da Linguagem, Universidade Estadual de Campinas, Campinas, SP, 2013.

TARALLO, F. Diagnosticando uma gramática brasileira: o português d'aquém e d'além mar ao final do século XIX. In: GUIMARÁES, Eduardo; ORLANDI, Eni (Org.). Língua e cidadania: o português no Brasil. Campinas: Pontes, 1996. p. 54-84.

VIDAL NETO, J. B. C. A Grammatica portugueza, de Júlio Ribeiro: um corte epistemológico na gramaticografia brasileira e a questão da língua portuguesa no Brasil. 2010. 141 p. Dissertação (Mestrado em Letras)- FFLCH, Universidade de São Paulo, São Paulo, SP, 2010.

Recebido: 03/10/2018

Aceito: $27 / 11 / 2018$

DOI: $10.5902 / 2179219435032$ 